\title{
The effect of soil type on the extraction of Insensitive High Explosive constituents using four
}

\section{conventional methods}

Temple, T.*a, Cipullo, S. ${ }^{\text {b }}$, Galante, E. ${ }^{\text {a }}$ Ladyman, M. ${ }^{\text {a }}$, Mai, N. ${ }^{\text {a }}$, Parry, T. ${ }^{\text {a }}$, Coulon, F. ${ }^{\text {b }}$

${ }^{\text {a }}$ Cranfield University, Centre for Defence Chemistry, Defence Academy of the United Kingdom, Shrivenham, SN6 7LA, UK

${ }^{\mathrm{b}}$ Cranfield University, School of Water, Energy and Environment, Cranfield, MK43 0AL, UK

*Corresponding author: t.temple@cranfield.ac.ukCranfield University, Centre for Defence Chemistry, Defence Academy of the United Kingdom, Shrivenham, SN6 7LA, UK

\begin{abstract}
Explosive contamination is commonly found at military and manufacturing sites [1-3]. Under current environmental legislation the extent of the contamination must be characterized by soil sampling and subsequent separation of the explosive contaminants from the soil matrix by extraction to enable chemical analysis and quantification [4]. It is essential that the extraction method can consistently recover explosive residue from a variety of soil types i.e. all materials that have not degraded or irreversibly bound to the matrix, so that any resultant risk is not underestimated. In this study, five different soil types with a range of organic content, particle size and $\mathrm{pH}$, were spiked with a mixture of RDX, DNAN, NQ and NTO at $50 \mathrm{mg} / \mathrm{kg}$ and were extracted using one of four one-step extraction methods: stirring, shaking, sonication, and accelerated solvent extraction (ASE). Analysis of the extraction efficiencies of the four methods found that they were broadly successful for the extraction of all IHE constituents from all five soils (an average of $84 \% \pm 14 \%$ recovery across 80 extractions). However, soils with high organic content (Total Organic Content (TOC) $\geq 2 \%$ ) were found to significantly affect
\end{abstract}


extraction efficiency and reproducibility. NTO and DNAN were the least consistent in extraction efficiency with poorest recovery of NTO as low as $37 \% \pm 2 \%$. Of the four tested methods shaking was found to be the most reproducible, though less efficient than stirring (64\%-91\%). ASE was found to have the most variable results for extraction of IHE constituents suggesting that ASE was the most affected by the different soil types. Therefore, it is recommended that the efficiency and reproducibility of the selected extraction method should be validated by extracting known concentrations of the IHE from the soil of interest and that any required correction factors are reported.

Keywords: 3,5-trinitroperhydro-1,3,5-triazine (RDX), 2,4-dinitroanisole (DNAN), 3-nitro1,2,4-triazolin-5-one (NTO), 1-nitroguanidine (NQ), Accelerated Solvent Extraction (ASE) 


\subsection{Introduction}

Explosive contamination is commonly found at military and manufacturing sites [1-3]. Under current environmental legislation the extent of the contamination must be identified by soil sampling and subsequent separation of the explosive contaminants from the soil matrix by extraction to enable chemical analysis and quantification [4]. It is essential that the extraction method can consistently recover available explosive residue i.e. materials that have not degraded or irreversibly bound to the matrix, so that any resultant risk is not underestimated. Much of the early work on the extraction of conventional explosives such as 2,4,6trinitrotoluene (TNT), 3,5-trinitroperhydro-1,3,5-triazine (RDX) and octahydro-1,3,5,7tetranitro-1,3,5,7-tetrazocine (HMX) from soil established standard procedures [5-7]. For example, soils are air dried prior to extraction to ensure that no water soluble contaminants are under-estimated during extraction i.e. with a non-water miscible solvent [6]. Solvents have also been compared and acetone (ACE), methanol $(\mathrm{MeOH})$ and acetonitrile $(\mathrm{ACN})$ have been identified as the most efficient, although ACE is often avoided when analysing HMX as the ACE peak overlaps with the HMX peak when detecting by High Performance Liquid Chromatography (HPLC) [5]. Research comparing extraction techniques for explosives from soil has disfavoured the commonly used Soxhlet extraction as extraction time can be up to 48 hours, and extraction efficiencies can be inconsistent due to irregular contact between the solvent and soil [5]. The same research recommend using sonicating (1- 4 hours) or shaking (24 hours), with sonication providing slightly higher recovery of the explosives tested (TNT, RDX and HMX).

One of the first methods developed specifically for extraction of conventional explosives from soil was by sonicating samples in ACN for 18 hours, which formed the basis for the commonly used SW-846 US EPA8330B standard. EPA8330B was used to extract very small quantities $(0.13-1.24 \mu \mathrm{g} / \mathrm{g})$ of RDX, TNT and HMX from soil with an accuracy of greater than $95 \%[8,9]$. 
The EPA8330B method was subsequently expanded and validated to include the extraction of nitro-aromatic, nitramine and nitro-ester explosives from soil by both sonication and shaking $[7,9,10]$.

In recent years, other extraction methods have been used to reduce extraction time and solvent use such as Accelerated Solvent Extraction (ASE), which uses high temperature and pressure to achieve full extraction of analytes in as little as fourteen minutes [11-13]. An ASE method has been successfully developed to extract conventional explosives such as RDX and TNT from an inert matrix (quartz sand) with extraction efficiencies between 90 and 120\% [14,15]. However, extraction recovery was dramatically reduced $(<70 \% \pm 14 \%$ of TNT) in acidic soil samples ( $\mathrm{pH} 5.26)$ with a high organic carbon content (3.89\%), most likely due to strong interactions between the soil and the explosives [14]. However, the development of this method demonstrated the applicability of ASE for the extraction of explosives despite concerns over thermal decomposition of the explosives at high temperatures. This research found that maintaining the temperature at $100^{\circ} \mathrm{C}$ was sufficient to promote fast and efficient extraction (twenty minutes) while also preserving the explosives [14].

Although the extraction of traditional explosives is well established [16-21], the current methods may not be suitable to extract new generation Insensitive High Explosives (IHE) from soil [22-24]. The IHE currently being brought into service can consist of mixtures of up to three of the following energetic materials: RDX, 2,4-dinitroanisole (DNAN), 3-nitro-1,2,4triazolin-5-one (NTO) and 1-nitroguanidine (NQ), which are likely to be deposited in combination on soil [25]. Extraction of these combinations from soil may be problematic as they have significantly different physicochemical properties and may be difficult to extract using typical extraction solvents e.g. ACE, ACN and MeOH (Table 1). Therefore, extracting with only organic solvent as per the EPA8330B standard may not be suitable. Despite concerns of the efficacy of EPA8330B for the extraction of IHE, the method has continued to be used 
by agitating (stir, shake or vortex) with only ACN, which may explain the low reported recoveries of NTO [26,27].

Table 1: Comparison of solubility and properties of IHE constituents

\begin{tabular}{|c|c|c|c|c|}
\hline IHE constituent & RDX & DNAN & NQ & NTO \\
\hline Chemical composition & $\mathrm{C}_{3} \mathrm{H}_{6} \mathrm{~N}_{6} \mathrm{O}_{6}$ & $\mathrm{C}_{7} \mathrm{H}_{6} \mathrm{~N}_{2} \mathrm{O}_{5}$ & $\mathrm{CH}_{4} \mathrm{~N}_{4} \mathrm{O}_{2}$ & $\mathrm{C}_{2} \mathrm{H}_{2} \mathrm{~N}_{4} \mathrm{O}_{3}$ \\
\hline Physical form ${ }^{1}$ & $\begin{array}{l}\text { White } \\
\text { crystalline } \\
\text { solid }\end{array}$ & $\begin{array}{l}\text { Tan to yellow } \\
\text { crystalline } \\
\text { solid }\end{array}$ & $\begin{array}{c}\text { Pale yellow } \\
\text { crystalline } \\
\text { solid }\end{array}$ & $\begin{array}{l}\text { White } \\
\text { crystalline } \\
\text { solid }\end{array}$ \\
\hline Water solubility $\left(\mathrm{g} / \mathrm{L} @ 25^{\circ} \mathrm{C}\right)^{2}$ & 0.06 & 0.28 & 3.0 & 16.6 \\
\hline ACN solubility $\left(\mathrm{g} / \mathrm{L} @ \mathbf{2 5}^{\circ} \mathrm{C}\right)$ & $55^{3}$ & Soluble $^{4}$ & NA & NA \\
\hline MeOH solubility (g/L @ $\left.25^{\circ} \mathrm{C}\right)$ & Slightly ${ }^{5}$ & Soluble $^{4}$ & Low $^{6}$ & Soluble $^{7}$ \\
\hline ACE solubility $\left(\mathrm{g} / \mathrm{L} @ \mathbf{2 5}^{\circ} \mathrm{C}\right)$ & $82^{7}$ & Soluble $^{7}$ & NA & $16.8^{7}$ \\
\hline Decomposition Temp $\left({ }^{\circ} \mathrm{C}\right)^{1}$ & 213 & $295^{3}$ & 232 & 273 \\
\hline Ignition Temp $\left({ }^{\circ} \mathrm{C}\right)^{1}$ & 210 & 347 & N.A. & $258-280$ \\
\hline
\end{tabular}

1. Akhavan J. 2011. The Royal Society of Chemistry; 2. Taylor, S. et al. 2015. Chemosphere, 134, p. 250; 3. Xing et al. 2012. Propellants, Explosives and Pyrotechnics, 37, p137; 4. Koutsospyros, A. et al. 2012. Journal of hazardous materials, 219, 75-81; 5. The Merck Index, p458; 6. Sitzmann, M.P. 1973. Silver Spring, Maryland. 7. Smith et al., 1999. Report: DSTO-TR-0796. N.A.: Data not available.

Therefore, new and adapted EPA8330B methods have been developed such as a two-step procedure for the extraction of RDX, DNAN and NTO from soil that used sonication with a 3:7 mixture of ACN and acidified water ( $0.1 \%$ trifluoroacetic acid), followed by 18 hours sonication in ACN [23]. As NTO is predominantly negatively charged at environmentally relevant $\mathrm{pH}(\mathrm{pH} 5-8)$, decreasing the $\mathrm{pH}$ of the water during the first step of the extraction was thought to reduce the affinity of NTO to soil making it easier to extract [28]. The second step (18 hr ACN sonication) was then used to fully extract any remaining DNAN and RDX as they are less soluble than NTO in water (Table 1). However, the second step did not appear to provide any added benefit as all explosives were recovered in the first step ( $>100 \%$ recovery) suggesting that one-step methods may still be appropriate for IHE extraction.

Extraction of IHE has been reported using a single step procedure by modifying the EPA8330B method to agitate the sample in a 1:1 mixture of ACN and water [28]. However, the study did not provide details of the extraction method or report the extraction efficiency rendering comparison and assessment of IHE constituent extraction difficult. 
Research conducted previously by the authors used an ACN/water (1:3) solvent system for the extraction of DNAN, NQ and NTO from soil using a modified ASE method for the extraction of conventional explosives [14,29]. DNAN and NQ were both efficiently extracted $(\sim 100 \%)$ from the two soil types (sandy and loamy), however only approximately $60 \%$ of NTO could be recovered therefore results were corrected for the missing mass with a recommendation for further development of the method [29].

As discussed above, to extract combinations of IHE constituents from soil it may be necessary to adapt EPA8330B to account for the differences in their physicochemical properties [30]. Satisfactory one-step extraction of all available IHE constituents has not been reported in the literature [29], which may underestimate the extent of contamination and therefore the risk. To date no studies regarding the efficiency and reproducibility of different IHE extraction methods in a variety of soil types have been published. In particular, this work focusses the efficient and reproducible extraction of a combination of IHE from soil using single step methods, which has not been consistently reported. Therefore, the aim of this work was to evaluate the efficiency of four one-step methods for the extraction of multiple constituents of IHE formulations from soil to demonstrate the significant variability between soil types. This was achieved by artificially contaminating five UK soil types with a mixture of RDX, DNAN, NQ and NTO. The explosives were then extracted from the soils by shaking, sonicating, stirring and ASE.

\section{Methodology}

\subsection{Materials}

Solvents (ACE, ACN and $\mathrm{MeOH}$ ), deionised water, DNAN and quartz sand were used as supplied (Fischer Scientific). NTO and NQ were synthesised by standard literature methods 
[31]. Extractions were carried out using a Stuart ${ }^{\mathrm{TM}}$ Orbital shaker, Bibby Scientific ${ }^{\mathrm{TM}}$ magnetic stirrer, Clifton Ultrasonic bath and a Dionex Accelerated Solvent Extraction 350.

\subsection{Soil collection and preparation}

Soils $(1 \mathrm{~kg})$ were collected from five locations around the UK including West Freugh (WF), Eskmeals (ESK), Pendine (PEN), Shoeburyness (SBN) and Wiltshire (WLT) (Figure 1). Soils were air-dried for 3 weeks to constant weight and passed through a 2-mm sieve to remove nonsoil material such as stones, debris etc. Particle size distribution was determined according to ASTM D 2487-11, and pH after twenty-four hours of shaking the soil in water. Soil texture was determined by the U.S Department of Agriculture (USDA) classification system based on grain size. Total Carbon Nitrogen Hydrogen (TCNH) content and TOC were determined from triplicate soil samples using Elementar Vario ELIII. The soil properties are summarised in Figure 1.

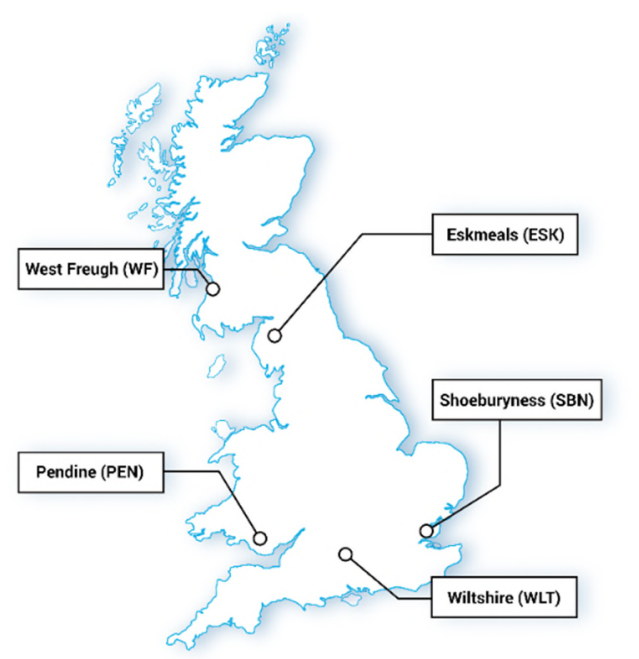

\begin{tabular}{|l|l|c|c|c|}
\hline & $\begin{array}{c}\text { Texture } \\
(\text { USDA) }\end{array}$ & $\mathbf{p H}$ & $\begin{array}{c}\text { TOC } \\
(\%)\end{array}$ & $\begin{array}{c}\text { Mode particle } \\
\text { size (mm) }\end{array}$ \\
\hline WF & Medium sand & 6.8 & 0.9 & 0.21 \\
\hline ESK & Medium sand & 6.5 & 2.9 & 0.21 \\
\hline PEN & Fine sand & 7.8 & 2.1 & 0.15 \\
\hline SBN & Loam & 7.9 & 6.5 & 0.06 \\
\hline WLT & Loamy sand & 7.9 & 0.4 & 1.00 \\
\hline
\end{tabular}

Figure 1: Collection locations for the five soil types and summary of soil characterisation.

\subsection{Preparation of stock solution}

RDX (268 mg), DNAN (253 mg), NQ (257 mg) and NTO (253 mg) were stirred in ACN (500 $\mathrm{mL}$ ) at ambient temperature for $24 \mathrm{~h}$ to make a $\sim 500 \mathrm{ppm}$ mixture stock solution referred to as ‘500 ppm stock solution’. 


\subsection{IHE extraction from soil}

\subsubsection{Extraction by method EPA8330B}

An inert matrix (10 g) (quartz sand) was prepared by contaminating with $1 \mathrm{~mL}$ of $500 \mathrm{ppm}$ solution of mixed RDX, DNAN, NQ and NTO in ACN. The quartz sand was evaporated to dryness (by weight) for four hours in a fume hood. The quartz sand was extracted by sonicating (1 hour) or shaking (18 hours) in ACN. The extract was filtered and analysed by HPLC.

\subsubsection{Identification of appropriate ASE solvent}

The ASE method used the same operating parameters as previously published [29]: $100^{\circ} \mathrm{C}$ oven temperature, 1500 psi pressure with a ten minute static time, $60 \%$ rinse volume and 200 second purge, taking approximately twenty minutes in total. An appropriate solvent was identified by evaluating the efficiency of extractions of IHE from an artificially contaminated inert matrix (quartz sand). The inert matrix ( $30 \mathrm{~g}$ ) was spiked with $1 \mathrm{~mL}$ of the $500 \mathrm{ppm}$ stock solution and evaporated to dryness. Samples were evaporated for twenty-four hours as evaporation was slower from the sand in the ASE stainless steel cells. All solvent systems tested included a percentage of water in $\mathrm{ACN}, \mathrm{MeOH}$ or ACE. The solvents were tested with $20 \%, 40 \%, 60 \%$, $80 \%$ and $100 \%$ water.

For $\mathrm{ACN} /$ water and $\mathrm{MeOH} /$ water solvent systems the extract was diluted to $150 \mathrm{~mL}$ in the extraction solvent and analysed by HPLC. For ACE/water extractions the solutions were evaporated (rotary evaporator) and re-dissolved in ACN $(10 \mathrm{~mL})$ for compatibility with the HPLC method.

\subsubsection{Extraction methods: shaking, sonication, stirring, ASE}

For shaking, sonicating and stirring $10 \mathrm{~g}$ of soil was weighed into amber vials and artificially contaminated with $1 \mathrm{~mL}$ of the 500 ppm stock solution and evaporated to dryness (4 hours). $\mathrm{ACN} /$ water 1:1 $(20 \mathrm{~mL})$ was added to the vials, as per methods reported in the literature [27]. Samples were mixed by hand for 30 seconds before placing the vial on the shaker, stirrer or in 
the sonic bath. Samples were shaken or stirred for 18 hours, or sonicated for one hour. Upon completion samples were left to settle for thirty minutes before filtration through a $0.2 \mu \mathrm{m}$ filter and analysis by HPLC.

For ASE, cells were filled with soil $(30 \mathrm{~g})$ spiked with $1 \mathrm{~mL} 500 \mathrm{ppm}$ stock solution and evaporated overnight. Samples were extracted at $100^{\circ} \mathrm{C}, 1500 \mathrm{psi}$ for twenty minutes, with a 5 minute static time and $60 \%$ rinse volume with $1: 4 \mathrm{MeOH} /$ water. The resulting extract $(\sim 60$ $\mathrm{mL}$ ) was made up to a $100 \mathrm{~mL}$ with extraction solvent and filtered prior to HPLC analysis. A summary of all four extraction methods is given in Error! Reference source not found..

Table 2: Summary of extraction methods.

\begin{tabular}{ccccc}
\hline Method & Solvent & $\begin{array}{c}\text { Solvent } \\
\text { Volume } \\
(\mathbf{m L})\end{array}$ & $\begin{array}{c}\text { Soil mass } \\
(\mathbf{g})\end{array}$ & $\begin{array}{c}\text { Time } \\
\text { (hours) }\end{array}$ \\
\hline Shaking & ACN/Water (1:1) & 20 & 10 & 18 \\
Stirring & ACN/Water (1:1) & 20 & 10 & 18 \\
Sonicating & ACN/Water (1:1) & 20 & 10 & 1 \\
ASE & MeOH/Water (1:4) & 60 & 30 & 0.5 \\
\hline
\end{tabular}

All extractions were repeated in triplicate and data averaged for analysis with standard error (SE) calculated by standard deviation $\times$ square root of the number of replicates (3). Errors in text are reported as $95 \%$ confidence values calculated by $\mathrm{SE} \times 2$. Results were normalised against the mass of explosive recovered from quartz sand using the same method assuming $100 \%$ extraction from the inert matrix.

\subsection{High Performance Liquid Chromatography}

HPLC was performed using a Waters-Alliance 2696 equipped with a Waters, 996 photodiode array detector (USA). The components were separated on a ZORBAX Eclipse plus $\mathrm{C}_{18}$ column $(100 \mathrm{~mm} \times 4.6 \mathrm{~mm}, \varnothing 3.5 \mu \mathrm{m})$ from Agilent technologies (Wilmington, DE, USA) maintained 
at $35^{\circ} \mathrm{C}$ Samples were injected with a syringe loading injector fitted with $20 \mu \mathrm{L}$ loop. Optimum chromatographic conditions were obtained with a linear gradient of $\mathrm{MeOH}$ (solvent $\mathrm{A}$ ) and water/0.1\% formic acid (solvent B) with a flow rate of $0.75 \mathrm{~mL} \mathrm{~min}^{-1}$ as previously reported [29]. The analytes were quantitated via UV absorbance with optimum sensitivity detected at $235 \mathrm{~nm}$ for RDX, 264 for NQ, 296 for DNAN and $315 \mathrm{~nm}$ for NTO. The calibration curve was obtained by plotting the concentration against corresponding peak area for each analytes. The slope and intercept were calculated through the least squares linear regression analysis using Microsoft Excel 2010. The HPLC calibration was performed for every batch of samples analysed, (no more than 15 samples at the time) by injecting in triplicate a mix IHE standard solution at concentrations ranging from 2 to $50 \mu \mathrm{g} \mathrm{mL}$ - Limit of Detection (LOD) and Limit of Quantification (LOQ) were analyzed by measuring the residual standard deviation of the responses and slopes of the regression equation of the calibration curve (root mean square error approach). Precision was determined by successive injections $(n=7)$ of the same samples at $22.5 \mu \mathrm{g} \mathrm{mL} \mathrm{m}^{-1}$.

Table 3: Summary of linearity, LOD, LOQ and precision for HPLC analysis of RDX, DNAN, NQ and NTO.

\begin{tabular}{|l|c|c|c|}
\hline $\begin{array}{c}\text { IHE mix solution } \\
\text { at } \mathbf{2 2 . 5} \boldsymbol{\mu} \mathbf{g} \mathbf{~ m L}^{-\mathbf{1}}\end{array}$ & $\begin{array}{c}\text { Linearity } \\
\left(\mathbf{R}^{\mathbf{2}}\right)\end{array}$ & $\begin{array}{c}\text { LOD/LOQ } \\
\left(\boldsymbol{\mu g} \mathbf{~ m L}^{-1}\right)\end{array}$ & $\begin{array}{c}\text { Precision } \\
(\mathbf{\%})\end{array}$ \\
\hline RDX & 0.9994 & $0.41 / 12.6$ & 0.8 \\
\hline DNAN & 0.9999 & $0.46 / 1.40$ & 0.6 \\
\hline NQ & 0.9996 & $0.53 / 1.60$ & 0.8 \\
\hline NTO & 0.9995 & $0.48 / 1.44$ & 0.8 \\
\hline
\end{tabular}

\subsection{Data analysis}

Data analysis was performed on independent sample triplicates. One-way-ANOVA test was used to investigate the significance and relationship between extraction method (shaking, sonication, stirring, and ASE) and percentage recovery of the four different explosives tested. To provide information on patterns or comparisons between specific groups post-hoc analysis 
was performed with Tukey's Test. Both ANOVA and Tukey's test were performed in R Studio using the "aov" and "TukeyHSD" function of the vegan library, respectively [32]. Principal component (PC) was computed with R Studio (Version 1.1.423 - (C) 2009-2018 RStudio, Inc.) to assess interrelationship among different variables, allowing detection and interpretation of sample similarities (groups). Data was pre-processed by scaling and centring with the function prcomp and plotted using "devtools" and "ggbiplot" libraries [33,34].

\subsection{Results and Discussion}

\subsection{EPA8330B method for IHE constituents}

In order to demonstrate that method EPA8330B required modification when extracting IHE, it was initially used as reported in the literature for extraction of the mixed IHE constituents, RDX, DNAN, NQ and NTO from an inert matrix (quartz sand). These constituents were selected as they are commonly used in IHE formulations. An inert matrix was artificially spiked with a 500 ppm solution of RDX, DNAN, NQ and NTO in ACN. The ACN was evaporated for four hours, the minimum time required for complete evaporation (determined by mass loss). An inert matrix was used to ensure that $100 \%$ of all available constituents were extracted and to avoid degradation or absorption of the IHE enabling clear identification of any inadequacies of the EPA8330B method. Samples were extracted by sonicating and shaking for 18 hours in ACN as described by the standard method EPA 8330.

As expected, the EPA8330B method was found not to be suitable for fully extracting all tested constituents of IHE even from an inert matrix. Results showed that RDX, DNAN and NQ were extracted by sonicating, $87 \%, 87 \%$ and $86 \%$ respectively, and shaking $87 \%, 88 \%$ and $87 \%$ respectively. It was assumed that errors were from handling and analysis accounted for the additional $12-14 \%$. However, NTO proved more difficult to fully extract by sonication and shaking with only $41 \%$ and $64 \%$ NTO recovered by sonication and shaking respectively 
(Figure 2). This was most likely due to the lower solubility of NTO in ACN, confirming findings from the literature (Figure 2) [26,27].

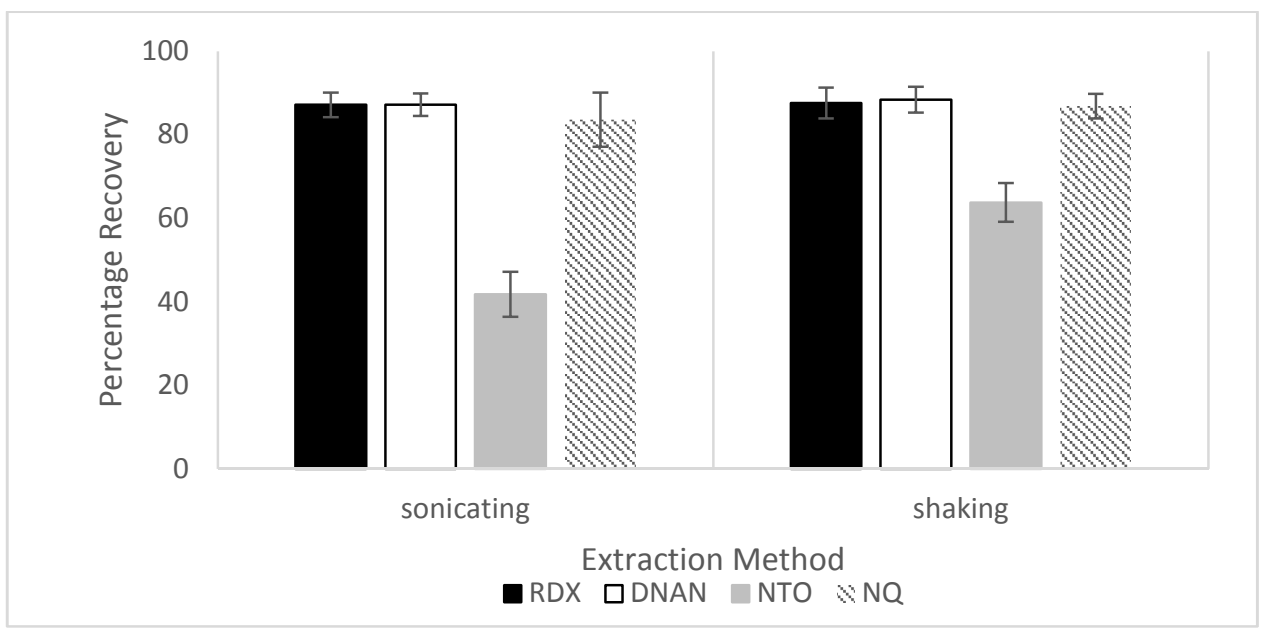

Figure 2: Extraction of RDX, DNAN, NQ and NTO from an inert matrix by EPA8330B method.

\subsection{Identification of appropriate ASE solvent}

To extract IHE from soil using ASE, the identification of appropriate solvent was required as the authors' previous work resulted in only $60 \%$ recovery of NTO, which was unsatisfactory. Therefore, guidance to do this was taken and adapted from the application note for the extraction of TNT and its degradation products from soil and a previous publication [15,29]. In previous work, extractions were carried out using a 14 minute method at $100^{\circ} \mathrm{C}, 1500 \mathrm{psi}$, with 5 minutes oven heating time and 5 minute static time in ACE or $\mathrm{MeOH}(50 \mathrm{~mL})$. As stated above a different solvent system including a percentage of water is required for the extraction of NTO and NQ. The ASE method was therefore screened with various mixtures of organic solvent to water ratios to identify the most effective solvent system. The application note recommended the use of $\mathrm{ACE}$ and $\mathrm{MeOH}$, but as $\mathrm{ACN}$ is most commonly used for extraction of traditional explosives such as RDX, it was also included [5].

Identification of an appropriate ASE solvent was carried out using an inert matrix (quartz sand) to eliminate sorption and reduce the likelihood of degradation. It was considered that the high 
temperatures employed in ASE could promote degradation, however the temperature was limited to $100^{\circ} \mathrm{C}$ for short periods (15-45 minutes) and significant degradation was considered to be unlikely.

Extractions of IHE from spiked quartz sand were carried out using various mixtures of $0-100 \%$ water and $\mathrm{ACE}, \mathrm{MeOH}$ or $\mathrm{ACN}$ with other operating parameters kept constant. Results showed that ACE was the least efficient solvent. Even with only $20 \%$ ACE in water it was not possible to extract any of the highly water soluble NTO (Figure 3). Extraction of RDX, DNAN and NQ was between $93 \%$ and $100 \%$ across all solvent systems. Surprisingly, with $100 \%$ water it was possible to extract $82 \%$ RDX, 91\% DNAN, $86 \%$ NQ and 92\% NTO. This was unexpected given the very low solubility of RDX and DNAN in water, but emphasizes the effect of using combined high temperatures and pressures to improve extraction as it is possible to heat solvents above their boiling point and substantially increase the solubility of chemicals in the extraction solvent [35].

Extraction efficiency when using at least $40 \% \mathrm{ACN}$ in water achieved high recovery $(91 \% \pm$ $10 \%$ ) for all IHE constituents, but extraction of NTO reduced significantly with higher percentages of ACN (Figure 3). The most efficient and reproducible extractions were achieved using a mixture of water and $\mathrm{MeOH}(94 \% \pm 5 \%)$. Even at low percentages of water in $\mathrm{MeOH}$ it was still possible to extract over $90 \%$ of all IHE constituents. However, $20 \% \mathrm{MeOH}$ in water was the most efficient solvent system extracting 100\% RDX, 94\% DNAN, 94\% NQ and 100\% NTO. This may be due to the higher polarity of $\mathrm{MeOH}$ compared to ACN which has less effect on the polarity of the combined water/organic solvent mixture enabling complete extraction of both aqueous and organic soluble constituents. Therefore, $20 \% \mathrm{MeOH}$ in water was used as the preferred solvent for all ASE extractions. 


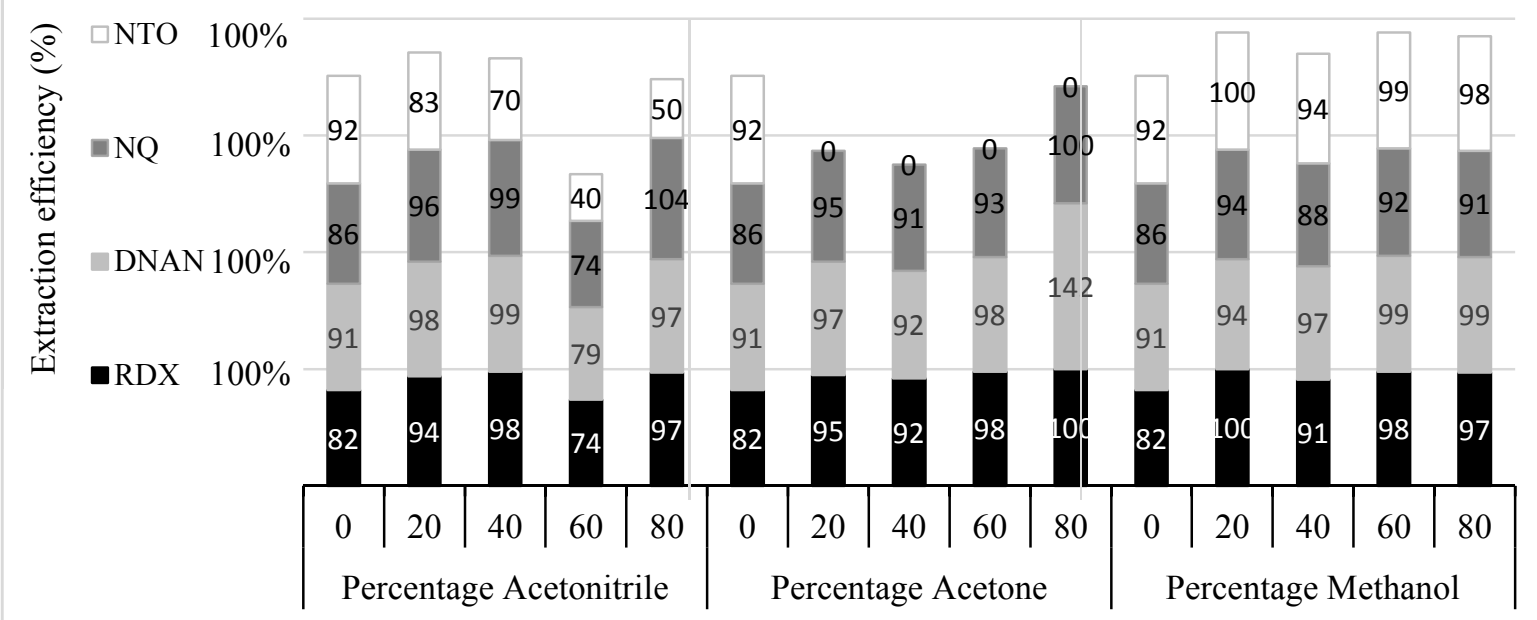

Percentage $(\%)$ of organic solvent in water

Figure 3: Comparison of ASE efficiency of IHE extraction from quartz sand using a range of solvent systems.

\subsection{Evaluation of extraction of IHE from different soils}

All four extraction methods were able to extract IHE constituents from soils, with an average of $84 \% \pm 14 \%$ recovery across all 80 extractions.

For all extraction methods, the soil type significantly affected the recovery values for all IHE $(\mathrm{p}<0.05)$. Tukey's Test $(95 \%$ confidence level $)$ was used to determine any significant differences between extraction methods. Only, stirring-ASE, stirring-shaking, and stirringsonication $(\mathrm{p}<0.05)$ demonstrated significant differences. No significant difference was observed for the other groups.

When results were analysed by Principal Component Analysis (PCA), ASE showed the greatest variance between extraction efficiencies for the four different IHE constituents from the five soils. Variance between results for the other three methods followed the order of sonicating $>$ stirring $>$ shaking (Figure 4). When comparing the results it was observed that extractions from the five soils could be grouped according to their organic content. ANOVA and Tukey's Test showed a significant difference $(\mathrm{p}<0.05)$ between results from ESK-PEN 
soils $(2.1-2.9 \%$ TOC) and WLT-WF soils $(0.4-0.9 \%$ TOC). A significant difference (p $<0.05)$ between results was also found between WLT-WF and SBN, and ESK-PEN and SBN. The soil with significantly higher TOC $(6.5 \%)(\mathrm{SBN})$ showed the greatest variance from the norm; confirming that high TOC can reduce extraction efficiency.

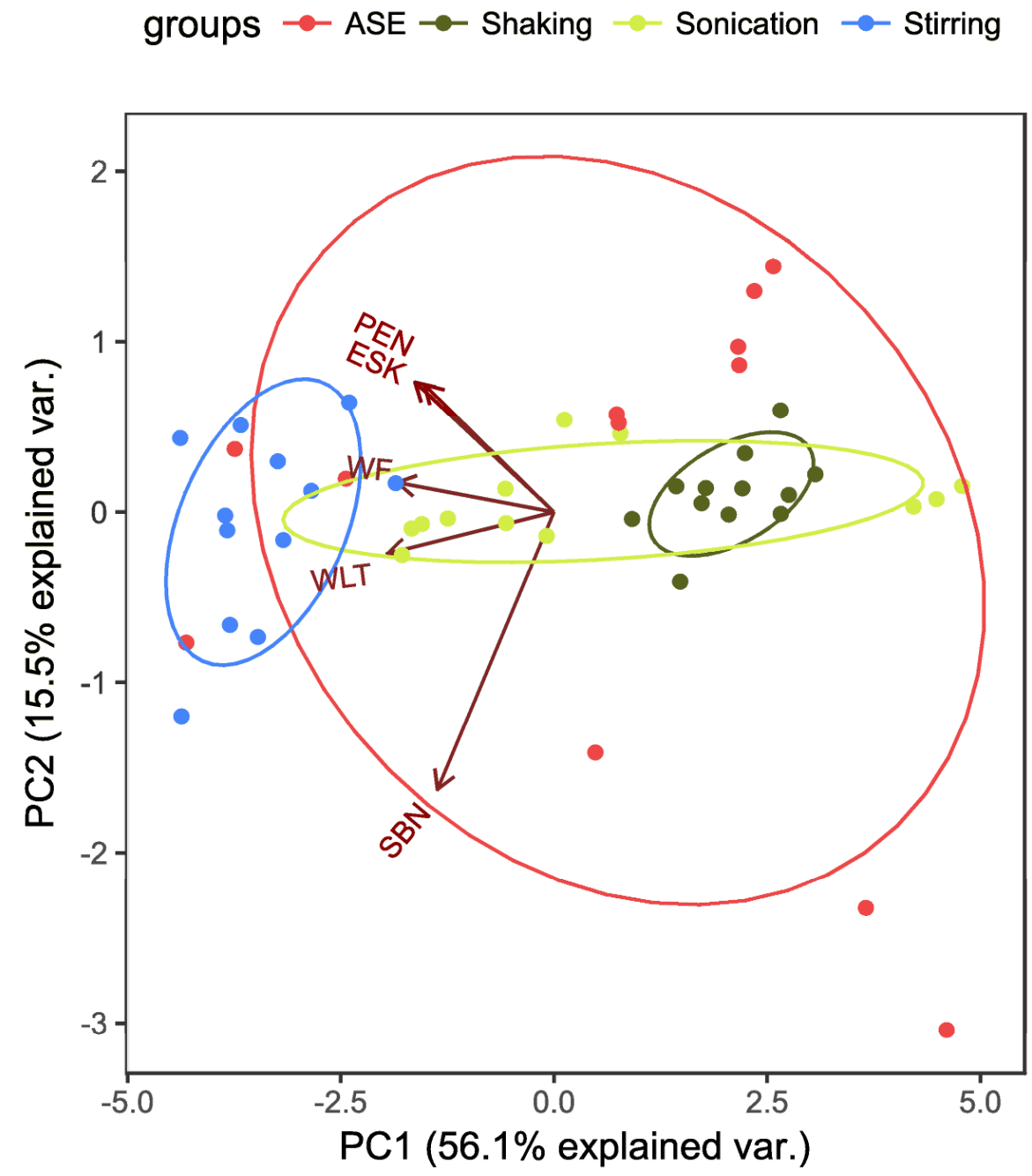

Figure 4: PCA of extraction efficiency for IHE from 5 soil types. 
Table 4: Extraction efficiencies for NTO, DNAN, RDX and NQ from five different soils using four extraction methods (error is reported at 95\% confidence and calculated as 2 times the Standard Error).

\begin{tabular}{|c|l|c|c|c|c|c|}
\hline \multirow{2}{*}{ Extraction method } & Explosive & \multicolumn{5}{|c|}{ Extraction efficiency (\%) per soil type } \\
\cline { 2 - 7 } & component & PEN & SBN & ESK & WF & WLT \\
\hline \multirow{3}{*}{$\begin{array}{c}\text { Accelerated Solvent } \\
\text { Extraction (ASE) }\end{array}$} & NTO & $50 \pm 85$ & $87 \pm 6$ & $37 \pm 2$ & $91 \pm 13$ & $89 \pm 2$ \\
\cline { 2 - 7 } & DNAN & $76 \pm 21$ & $51 \pm 3$ & $57 \pm 5$ & $98 \pm 2$ & $93 \pm 5$ \\
\cline { 2 - 7 } & RDX & $99 \pm 27$ & $84 \pm 8.2$ & $85 \pm 4$ & $110 \pm 3$ & $102 \pm 2$ \\
\cline { 2 - 7 } & NQ & $74 \pm 1.2$ & $67 \pm 4$ & $84 \pm 4$ & $94 \pm 86$ & $86 \pm 2$ \\
\hline \multirow{5}{*}{ Shaking } & NTO & $77 \pm 2$ & $74 \pm 4$ & $76 \pm 0.1$ & $75 \pm 4$ & $91 \pm 3$ \\
\cline { 2 - 7 } & DNAN & $69 \pm 2$ & $74 \pm 2$ & $80 \pm 3$ & $95 \pm 8$ & $82 \pm 4$ \\
\cline { 2 - 7 } & RDX & $64 \pm 2$ & $66 \pm 3$ & $75 \pm 2$ & $92 \pm 6$ & $81 \pm 4$ \\
\cline { 2 - 7 } & NQ & $64 \pm 2$ & $71 \pm 1.5$ & $79 \pm 2$ & $90 \pm 6$ & $82 \pm 5$ \\
\hline \multirow{5}{*}{ Sonication } & NTO & $84 \pm 2$ & $71 \pm 1$ & $59 \pm 3$ & $72 \pm 4$ & $73 \pm 2$ \\
\cline { 2 - 7 } & DNAN & $94 \pm 1$ & $77 \pm 7$ & $75 \pm 5$ & $99 \pm 3$ & $96 \pm 4$ \\
\cline { 2 - 7 } & RDX & $90 \pm 4$ & $73 \pm 5$ & $69 \pm 3$ & $98 \pm 3$ & $93 \pm 4$ \\
\cline { 2 - 7 } & NQ & $94 \pm 2$ & $80 \pm 3$ & $73 \pm 7$ & $97 \pm 4$ & $96 \pm 4$ \\
\hline \multirow{5}{*}{ Stirring } & NTO & $96 \pm 1$ & $95 \pm 5$ & $89 \pm 3$ & $105 \pm 3$ & $103 \pm 2$ \\
\cline { 2 - 7 } & DNAN & $90 \pm 1$ & $84 \pm 5$ & $104 \pm 3$ & $107 \pm 1$ & $100 \pm 4$ \\
\cline { 2 - 6 } & RDX & $92 \pm 2$ & $83 \pm 4$ & $102 \pm 4$ & $110 \pm 3$ & $102 \pm 5$ \\
\cline { 2 - 6 } & NQ & $85 \pm 1$ & $77 \pm 4$ & $96 \pm 5$ & $103 \pm 3$ & $102 \pm 2$ \\
\hline
\end{tabular}

\subsubsection{Extraction by ASE}

ASE was the least consistent for extraction of IHE constituents, suggesting this technique was the most affected by differences in soil type (Supplementary Fig. 1-4). Of the explosives extracted NTO and DNAN had the least consistent extraction efficiency with poorest recovery of NTO as low as $37 \% \pm 2 \%$ from ESK soil with large discrepancies between identical replicates (Figure 5). Extraction efficiency of DNAN decreased with increasing TOC of the soil, with lowest recovery observed for SBN soil with $6.5 \%$ TOC $(51 \% \pm 3 \%)$. This may be due to the tendency for DNAN to sorb to soils with high organic content, therefore it is possible that the short extraction time (10 min static time) used for ASE is not sufficient to desorb all DNAN even at high temperature and pressure. Conversely, for soils with lower organic content extraction achieved almost 100\% (WLT and WF 93\% $\pm 5 \%$ and 98\% $\pm 2 \%$ respectively), suggesting that repeated extractions or a longer extraction time may improve efficiency for soils with high TOC (Figure 5). 


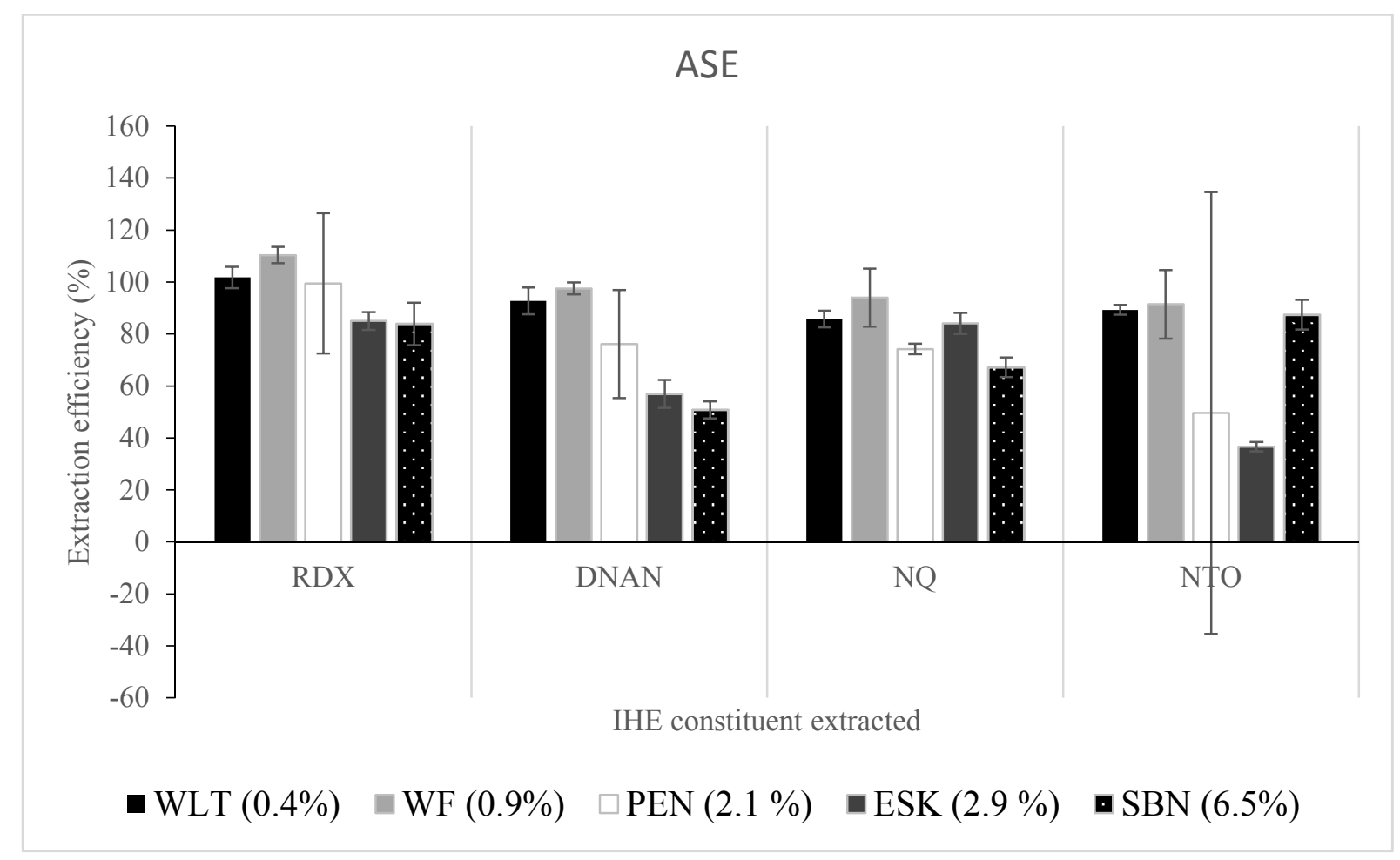

Figure 5: ASE extraction efficiency for IHE constituents from five soil types arranged by TOC.

Extraction efficiency of NTO was high from soils with low TOC $89 \% \pm 2 \%$ and $91 \% \pm 11 \%$ respectively from WLT $(0.4 \%)$ and WF $(0.9 \%)$ (Table 4$)$. However, from soils with higher organic content the percentage of NTO extracted was lower: $50 \% \pm 43 \%$ (PEN) and $37 \pm 2 \%$ ESK) (Table 4) (Figure 5). Although NTO degrades in soils with high TOC, the IHE constituents were only exposed to soil for a maximum of 24 hours, which makes it unlikely to account for the $60 \%$ unrecovered material [29]. In addition, SBN soil with the highest TOC $(6.5 \%)$ did not fit the trend of decreasing recovery with increasing TOC, and good extraction efficiency was achieved $(87 \% \pm 5 \%)$. The high extraction efficiency for NTO in SBN soil may be due to a low mode particle size, which is significantly lower than for the other soils tested with a large percentage of silt (0.002-0.0063). Reducing particle size or increasing surface area is often cited as one of the ways to improve extraction efficiency and reproducibility [36]. The naturally low mode particle size of this soil may have therefore contributed to an increased 
extraction efficiency despite the high organic content, highlighting the importance of sample preparation (particularly grinding) for high organic content soils.

Table 5: Extraction efficiency of NTO by ASE compared to organic content and mode particle size.

\begin{tabular}{cccc}
\hline Soil Name & $\begin{array}{c}\text { NTO Extraction } \\
\text { Efficiency }(\%)\end{array}$ & $\begin{array}{c}\text { Total Organic } \\
\text { Content }(\%)\end{array}$ & $\begin{array}{c}\text { Particle Size } \\
(\mathbf{m m})\end{array}$ \\
\hline WLT & $89 \pm 2$ & 0.4 & $0.5-1$ \\
WF & $91 \pm 11$ & 0.9 & 0.2 \\
PEN & $50 \pm 43$ & 2.1 & 0.2 \\
ESK & $37 \pm 2$ & 2.9 & 0.2 \\
SBN & $87 \pm 5$ & 6.5 & 0.063 \\
\hline
\end{tabular}

Overall, ASE was more successful for the extraction of RDX and NQ from soil averaging 96\% $\pm 11 \%$ and $81 \% \pm 11 \%$ respectively compared to DNAN and NTO. Although, RDX extraction efficiency tended to be slightly lower for soils with higher organic content e.g. for SBN (67\% $\pm 3 \%)$ and PEN $(74 \% \pm 1 \%)$ (Figure 5), no clear trend between extraction efficiency and the soil properties i.e. organic content, $\mathrm{pH}$ and particle size could be drawn (Supplementary Fig. 5). Therefore, these observations may be due to other characteristics of the soil or inconsistencies in the ASE method. Further optimisation of the ASE method when using different soils may help to improve consistency and efficiency. The method used for this comparison could be used as a starting point for optimisation of the number of extraction cycles and extraction with a sequence of solvents.

\subsubsection{Extraction by sonication and stirring}

Sonication and stirring behaved similarly in variance between extraction efficiency for different soil types (Figure 4). However, stirring was more efficient averaging $96 \% \pm 9 \%$ compared to $83 \% \pm 12 \%$ for sonication across all soils and explosives (15 extractions). Sonication achieved low extraction for NTO (72\%), whilst recovery of DNAN, RDX and NQ 
averaged above $87 \% \pm 11 \%$ (Figure 6 ), with generally poorer recovery in the higher TOC soils (ESK and SBN). The low extraction efficiency of NTO using sonication may be due to the shorter extraction time (1 hour) compared to shaking and stirring (18 hours), which may not give enough time for the NTO to fully migrate from the soil into the extraction solvent $(1: 1$ $\mathrm{ACN} /$ water). Extraction may be improved if the extraction is continued for longer, however for sonication this is often limited by the equipment. This was supported by results for ASE for which a mixture of $80 \%$ water and $\mathrm{MeOH}$ was required to fully extract $\mathrm{NTO}$, which is a more polar solvent mixture and therefore more likely to solubilise NTO. As extraction efficiency for RDX, DNAN and NQ was reasonably high the sonication method is a suitable technique for these materials. Slight variability was observed between different soil types, particularly for soils with higher TOC (ESK, SBN) suggesting a need to fully understand the extraction efficiency so that results can be corrected accordingly.

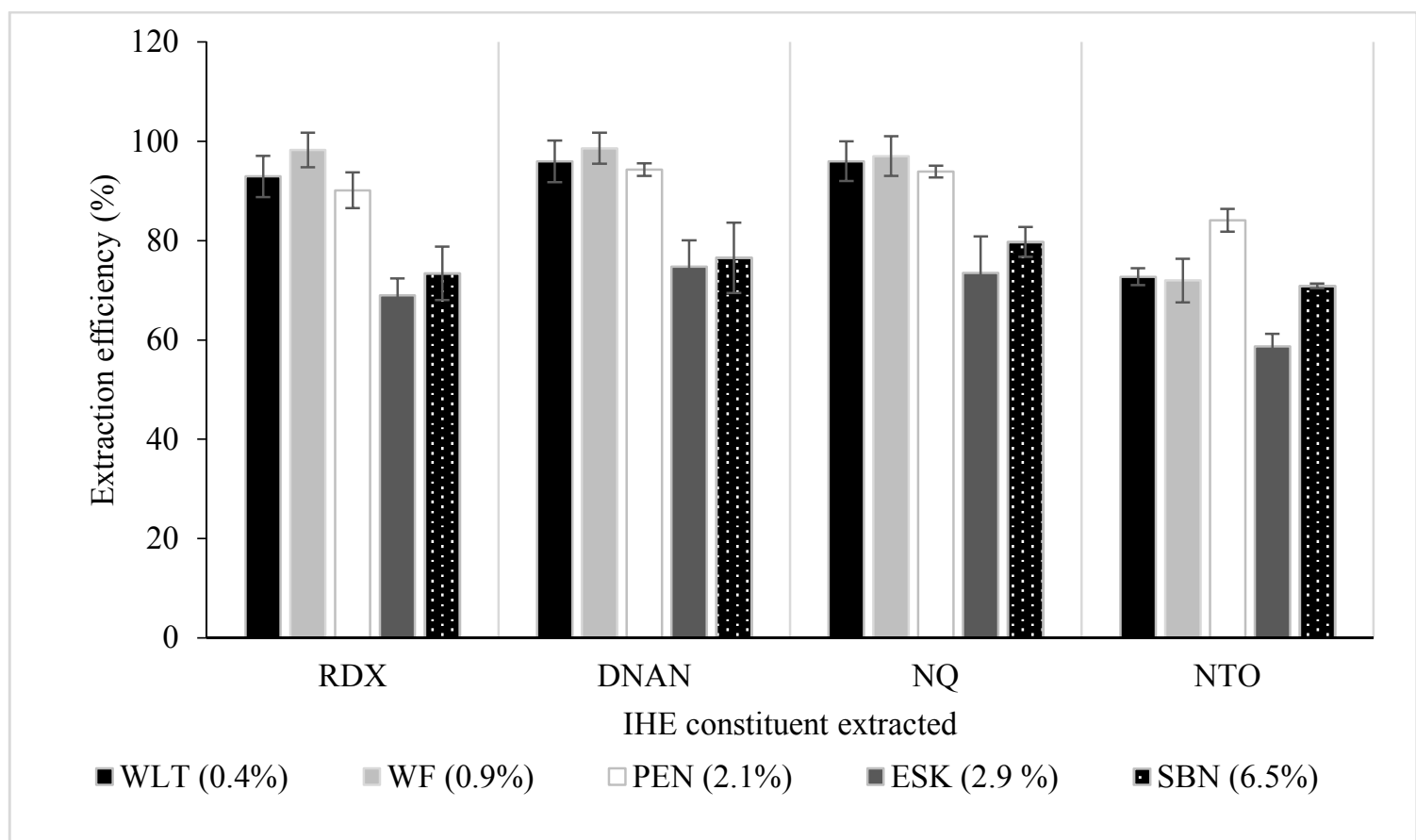

Figure 6: Efficiency of extraction of IHE constituents from five soil types arranged by TOC by sonication. 
Stirring averaged almost complete recovery for all IHE constituents from all soils (RDX 102\% $\pm 11 \%$, DNAN $97 \%, \pm 10 \%$, NQ $92 \% \pm 11 \%$ and NTO $97 \% \pm 7 \%$ ). Of interest the extraction of NTO by stirring was the most reproducible, which is in complete contrast to sonication and ASE in which NTO proved difficult to extract. Even though stirring was carried out using the same solvent system as sonication NTO recovery was more efficient. This may be due to the reduced time used for sonication extractions.

\subsubsection{Extraction by shaking}

Shaking was the most reproducible method with the least variability between results, suggesting this method was the least affected by soil properties. However, the extraction efficiency was lower than the other tested methods averaging $78 \% \pm 9 \%$ across all soils and explosives (15 extractions) compared to $83 \% \pm 12 \%$ for sonication, $96 \% \pm 9 \%$, for stirring and $81 \pm 19 \%$ for ASE (Supplementary Fig. 1-4). These results were surprising as shaking is one of the most commonly used extraction methods and is often reported as being efficient and reproducible, whereas these results show that for IHE shaking is consistent but inefficient. Therefore, when extracting by shaking results should be corrected for the unaccounted mass. 


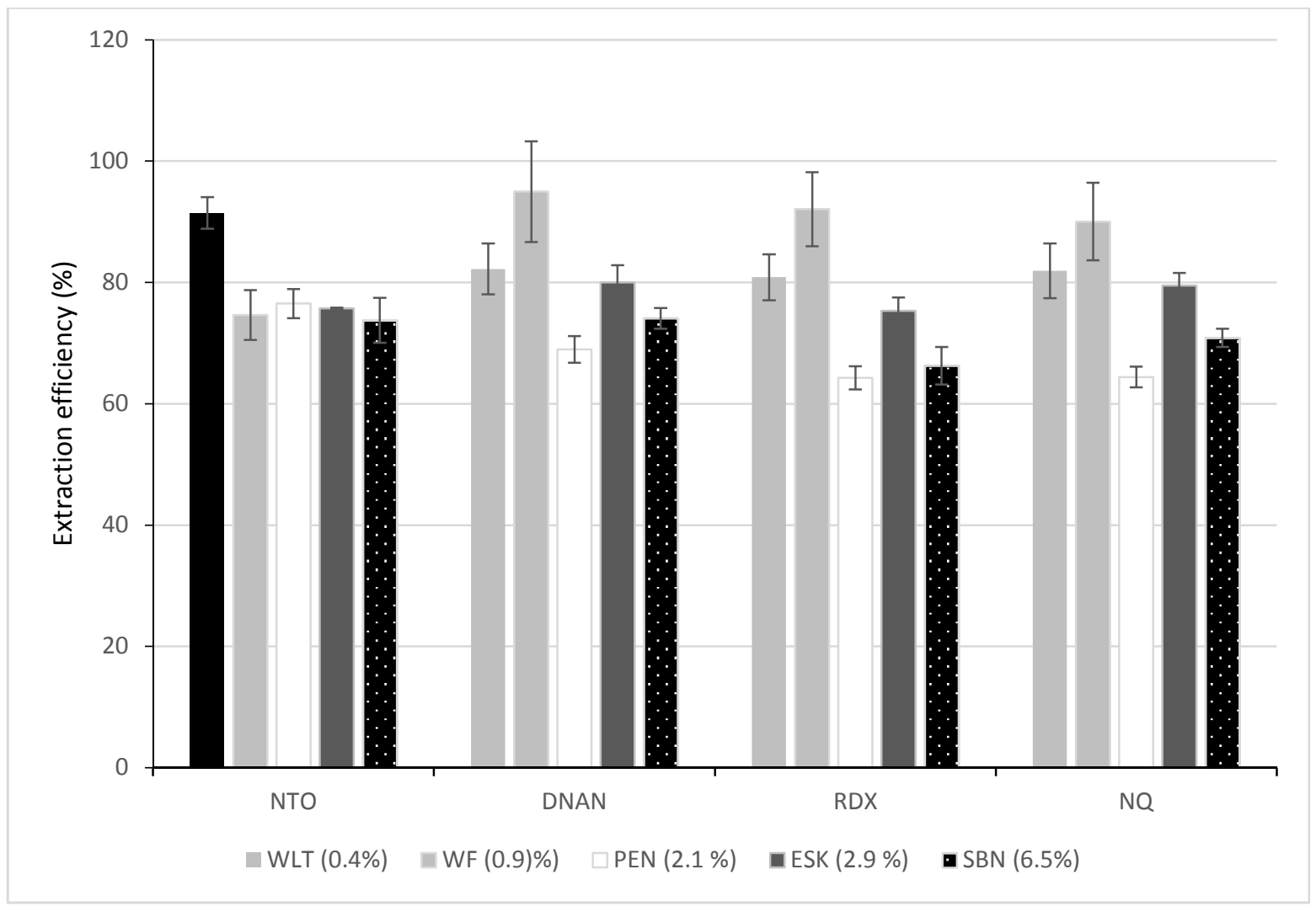

Figure 7: Comparison of extraction of RDX, DNAN, NQ and NTO from five soils by shaking.

Table 6 summarises the experimental results highlighting that on average extraction of IHE by shaking was found to be the least affected by soil type, though average recovery was lower than for extraction by shaking. The shorter methods, ASE and shaking were found to be more affected by soil type, with lower explosive recovery from higher TOC soils, particularly for the IHE more likely to sorb to soil (NTO and DNAN). Therefore, it is suggested that for soil types with low organic content efficient extraction can be achieved using any of the four methods and can be completed quickly (less than an hour). However, for soils with higher organic content longer solvent exposure times (18 hours) can improve extraction, though correction factors are still required. 
Table 6: Summary of extraction methods and soil extraction results.

\begin{tabular}{|l|c|l|c|c|}
\hline Method & $\begin{array}{c}\text { Average } \\
\text { Extraction } \\
\text { Efficiency } \\
\mathbf{( \% )}\end{array}$ & $\begin{array}{c}\text { Dependence on soil type } \\
\text { (PCA) }\end{array}$ & Solvent (Volume) & Time \\
\hline ASE & $81 \pm 8$ & $\begin{array}{l}\text { Poorer recovery in higher } \\
\text { TOC and larger mode } \\
\text { particle size soils }\end{array}$ & $\begin{array}{c}1: 4 \mathrm{MeOH}: \text { Water } \\
(60 \mathrm{~mL})\end{array}$ & $20 \mathrm{~min}$ \\
\hline Sonication & $83 \pm 1$ & $\begin{array}{l}\text { Poorer recovery in higher } \\
\text { TOC soil }\end{array}$ & $\begin{array}{c}1: 1 \mathrm{ACN}: \text { Water } \\
(20 \mathrm{~mL})\end{array}$ & $1 \mathrm{hr}$ \\
\hline Stirring & $96 \pm 1$ & $\begin{array}{l}\text { Limited effect from soil } \\
\text { type }\end{array}$ & $\begin{array}{c}1: 1 \mathrm{ACN}: \mathrm{Water} \\
(20 \mathrm{~mL})\end{array}$ & $18 \mathrm{hrs}$ \\
\hline Shaking & $78 \pm 1$ & Least affected by soil type & $\begin{array}{c}1: 1 \mathrm{ACN}: \mathrm{water} \\
(20 \mathrm{~mL})\end{array}$ & $18 \mathrm{hrs}$ \\
\hline
\end{tabular}

\subsection{Conclusion}

This study confirmed that it is necessary to adapt the standard explosive extraction method EPA8330B to achieve consistent and efficient extraction of IHE constituents from soil in a single step. To achieve this, a high percentage of water in an organic solvent $(\geq 50 \%)$ is essential for efficient extraction. This research also highlights the significant effect that soil type has on the extraction efficiency of IHE, which has not previously been reported in the literature. This research has shown that the most reproducible extraction method tested was shaking, while the most efficient method was stirring, which recovered almost $100 \%$ of all IHE from the five soil types using 1:1 ACN: water. This work demonstrates that any of the tested extraction methods could be used based on practicalities and available resources providing they are accompanied by a statement of efficiency and any correction factors. These results are beneficial for researchers in the field of environmental explosive science working on the fate and behaviour of IHE in training areas around the world, and highlights the importance of understanding soil type and extraction efficiency. It is expected that the use of these IHE will increase, and therefore this work will provide researchers with confidence in one-step extractions of combinations of these materials. 


\subsection{Acknowledgements}

The authors thank Dr Michael Piperakis for his contribution to the experimental work. The authors would also like to thank Clare Pratchett, Cranfield University, for producing the graphical abstract. This work was funded by Cranfield University. This research did not receive any specific grant from funding agencies in the public commercial or not for profit sectors.

\subsection{References}

[1] A.D. Hewitt, T.F. Jenkins, M.E. Walsh, M.R. Walsh, S. Taylor, RDX and TNT residues from live-fire and blow-in-place detonations, Chemosphere. 61 (2005) 888-894. doi:10.1016/J.CHEMOSPHERE.2005.04.058.

[2] J. Clausen, J. Robb, D. Curry, N. Korte, A case study of contaminants on military ranges: Camp Edwards, Massachusetts, USA, Environ. Pollut. 129 (2004) 13-21. doi:10.1016/j.envpol.2003.10.002.

[3] M.R. Walsh, M.E. Walsh, C.A. Ramsey, S. Brochu, S. Thiboutot, G. Ampleman, Perchlorate contamination from the detonation of insensitive high-explosive rounds, J. Hazard. Mater. 262 (2013) 228-233. doi:10.1016/j.jhazmat.2013.08.045.

[4] J.R. Dean, Extraction Techniques in Analytical Sciences, 1st ed., John Wiley \& Sons, Ltd., Chichester, 2009. doi:10.1002/9780470682494.

[5] T.F. Jenkins, D.C. Leggett, Comparison of extraction techniques and solvents for explosive residues in soil (Special Report 85-22), Hanover, 1985. http://www.dtic.mil/dtic/tr/fulltext/u2/a166474.pdf (accessed August 2, 2018).

[6] J. Cragin, D. Leggett, B. Foley, P. Schumacher, TNT, RDX and HMX explosives in soils and sediments: Analysis techniques and drying losses, Hanover, 1985. http://www.dtic.mil/docs/citations/ADA163278 (accessed August 2, 2018).

[7] M.E. Walsh, T.F. Jenkins, P.S. Schnitker, J.W. Elwell, M.H. Stutz, Evaluation of SW846 Method 8330B for Characterization of Sites Contaminated with Residues of High Explosives, Hanover, 1993. http://www.dtic.mil/dtic/tr/fulltext/u2/a268700.pdf (accessed August 2, 2018).

[8] T.F. Jenkins, M.E. Walsh, Development of an analytical method for exploisves resdiues in soil, Hanover, 1987.

[9] US Environmental Protection Agency, EPA Method 8330B (SW-846): Nitroaromatics and Nitramines by High Performance Liquid Chromatography (HPLC), 2006. https://www.epa.gov/sites/production/files/2015-07/documents/epa-8330b.pdf (accessed June 13, 2017). 
[10] M.E. Walsh, T.F. Jenkins, P.G. Thorne, Laboratory and analytical methods for explosives residues in soil, J. Energ. Mater. 13 (1995) 357-383. doi:10.1080/07370659508019392.

[11] X. Lou, H.-G.J. Janssen, C.A. Cramers, Parameters Affecting the Accelerated Solvent Extraction of Polymeric Samples, Anal. Chem. 69 (1997) 1598-1603. doi:10.1021/AC960766A.

[12] J.A. Fisher, M.J. Scarlett, A.D. Stott, Accelerated Solvent Extraction: An Evaluation for Screening of Soils for Selected U.S. EPA Semivolatile Organic Priority Pollutants, Environ. Sci. Technol. 31 (1997) 1120-1127. doi:10.1021/ES9606283.

[13] B.E. Richter, B. a Jones, J.L. Ezzell, N.L. Porter, D. Corporation, T. Way, P.O. Box, Accelerated Solvent Extraction: A Technique for Sample Preparation, Anal. Chem. 68 (1996) 1033-1039. doi:10.1021/ac9508199.

[14] S. Campbell, R. Ogoshi, G. Uehara, Q.X. Li, Trace Analysis of Explosives in Soil: Pressurized Fluid Extraction and Gas and Liquid Chromatography-Mass Spectrometry, J. Chromatogr. Sci. 41 (2003) 284-288. doi:10.1093/chromsci/41.6.284.

[15] Dionex, Application Note 328: Extraction of Explosives from soils by Accelerated Solvent Extraction (ASE), Sunnyvale, CA, 2011. https://assets.thermofisher.com/TFSAssets/CMD/Application-Notes/AN-328-ASE-Explosives-Soils-LPN0888-EN.pdf.

[16] M.-C. Lapointe, R. Martel, S.F. Lange, S. Coté, Effect of energetic materials wettability on their outdoor effective elution rate, J. Hazard. Mater. 311 (2016) 194-202. doi:10.1016/J.JHAZMAT.2016.02.075.

[17] A.L.L. Russell, J.M.M. Seiter, J.G.G. Coleman, B. Winstead, A.J.J. Bednar, Analysis of munitions constituents in IMX formulations by HPLC and HPLC-MS, Talanta. 128 (2014) 524-530. doi:10.1016/j.talanta.2014.02.013.

[18] J.L. Thomas, C.C. Donnelly, E.W. Lloyd, R.F. Mothershead, M.L. Miller, Development and validation of a solid phase extraction sample cleanup procedure for the recovery of trace levels of nitro-organic explosives in soil, Forensic Sci. Int. 284 (2018) 65-77. doi:10.1016/J.FORSCIINT.2017.12.018.

[19] M.R. Walsh, S. Thiboutot, M.E. Walsh, G. Ampleman, Controlled expedient disposal of excess gun propellant, J. Hazard. Mater. 219-220 (2012) 89-94. doi:10.1016/J.JHAZMAT.2012.03.060.

[20] G.A. Pascoe, K. Kroeger, D. Leisle, R.J. Feldpausch, Munition constituents: Preliminary sediment screening criteria for the protection of marine benthic invertebrates, Chemosphere. 81 (2010) 807-816. doi:10.1016/J.CHEMOSPHERE.2010.06.077.

[21] E. Holmgren, S. Ek, A. Colmsjö, Extraction of explosives from soil followed by gas chromatography-mass spectrometry analysis with negative chemical ionization, J. Chromatogr. A. 1222 (2012) 109-115. doi:10.1016/J.CHROMA.2011.12.014.

[22] S. Taylor, D.B. Ringelberg, K. Dontsova, C.P. Daghlian, M.E. Walsh, M.R. Walsh, Insights into the dissolution and the three-dimensional structure of insensitive munitions formulations., $\quad$ Chemosphere. $\quad 93 \quad$ (2013) 1782-8. doi:10.1016/j.chemosphere.2013.06.011.

[23] D. Felt, L. Gurtowski, C.C. Nestler, J. Johnson, S. Larson, A two-stage extraction procedure for insensitive munition (IM) explosive compounds in soils, Chemosphere. 
165 (2016) 18-26. http://linkinghub.elsevier.com/retrieve/pii/S0045653516311298 (accessed September 23, 2016).

[24] N. Mark, J. Arthur, K. Dontsova, M. Brusseau, S. Taylor, J. Šimůnek, Column transport studies of 3-nitro-1,2,4-triazol-5-one (NTO) in soils, Chemosphere. 171 (2017) 427434. doi:10.1016/j.chemosphere.2016.12.067.

[25] T. Richard, J. Weidhaas, Biodegradation of IMX-101 explosive formulation constituents: 2,4-dinitroanisole (DNAN), 3-nitro-1,2,4-triazol-5-one (NTO), and nitroguanidine, J. Hazard. Mater. 280 (2014) 561-569. doi:10.1016/j.jhazmat.2014.08.042.

[26] J.D. Arthur, N.W. Mark, S. Taylor, J. Šimůnek, M.L. Brusseau, K.M. Dontsova, Dissolution and transport of insensitive munitions formulations IMX-101 and IMX-104 in saturated soil columns, Sci. Total Environ. 624 (2018) 758-768. doi:10.1016/J.SCITOTENV.2017.11.307.

[27] N.W. Mark, Batch and Column Transport Studies of Environmental Fate of 3-nitro-1, 2, 4-triazol-5-one ( NTO ) in Soils, The University of Arizona, 2016.

[28] N. Mark, J. Arthur, K. Dontsova, M. Brusseau, S. Taylor, Adsorption and attenuation behavior of 3-nitro-1,2,4-triazol-5-one (NTO) in eleven soils, Chemosphere. 144 (2016) 1249-1255. doi:10.1016/j.chemosphere.2015.09.101.

[29] T. Temple, M. Ladyman, N. Mai, E. Galante, M. Ricamora, R. Shirazi, F. Coulon, Investigation into the environmental fate of the combined Insensitive High Explosive constituents 2,4-dinitroanisole (DNAN), 1-nitroguanidine (NQ) and nitrotriazolone (NTO) in soil, Sci. Total Environ. 625 (2018) 1264-1271. doi:10.1016/j.scitotenv.2017.12.264.

[30] T. Richard, J. Weidhaas, Dissolution , sorption , and phytoremediation of IMX-101 explosive formulation constituents : 2 , 4-dinitroanisole ( DNAN ), J. Hazard. Mater. 280 (2014) 561-569. doi:10.1016/j.jhazmat.2014.08.042.

[31] K.-Y. Lee, M.D. Coburn, 3-nitro-1,2,4,-triazol-5-one, a less sensitive explosive, $4,733,610,1988$.

[32] A.J. Oksanen, F.G. Blanchet, R. Kindt, P. Legen-, P.R. Minchin, R.B.O. Hara, G.L. Simpson, P. Soly-, M.H.H. Stevens, H. Wagner, Package ‘ vegan ,' (2011).

[33] A. Hadley, J. Hester, W. Chang, M.J. Hester, Package ' devtools ,' (2018).

[34] H. Wickham, ggplot2: Elegant Graphics for Data Analysis, (2016).

[35] H.J. Vandenburg, A.A. Clifford, K.D. Bartle, R.E. Carlson, J. Carroll, I.D. Newton, A simple solvent selection method for accelerated solvent extraction of additives from polymers, Analyst. 124 (1999) 1707-1710. doi:10.1039/a904631c.

[36] M.E. Walsh, C.A. Ramsey, T.F. Jenkins, The effect of particle size reduction by grinding on subsampling variance for explosives residues in soil, Chemosphere. 49 (2002) 12671273. doi:10.1016/S0045-6535(02)00528-3. 